\title{
bioethics
}

THE INVISIBLE DISCRIMINATION BEFORE OUR EYES: A BIOETHICAL ANALYSIS

\begin{tabular}{|r|l|}
\hline Journal: & Bioethics \\
\hline Manuscript ID & Draft \\
\hline Manuscript Type: & Original Article \\
\hline Keywords: & Lookism, allocation of resources, cosmetic surgery, discrimination \\
\hline & \\
\hline
\end{tabular}

SCHOLARONE

Manuscripts 


\section{THE INVISIBLE DISCRIMINATION BEFORE OUR EYES: A BIOETHICAL ANALYSIS}

\section{THE STORY OF JANE}

Jane had always known, deep down herself, that her life would have fared better had she not be affected by her "condition".

She had fond memories of her parents, they were really nice people, but she always thought that they seemed to like her siblings better. And it was not just her parents who treated her differently: it was her parents' friends and family too. As a child, whenever she started a tantrum, the adults around her looked very annoyed, but whenever her siblings had one of their tantrums, there was always someone ready to cheer them up.

And at the kindergarten things did not fare better. Jane's siblings were the ones other kids wanted to play and share toys with, while Jane had to make an extra effort to be involved in their games.

Later, at school, teachers seemed to just assume that Jane's was the least smart member of the family. They would encourage her siblings to take more subjects and to try new activities, but Jane did not get the same kind of encouragement and positive feedback, although she was certainly not less smart than her siblings.

A few years after college, both Jane and one of her siblings found jobs as lawyers. They had a very similar CV, same training and experience. But her sibling ended up getting a much better job, earning about $12 \%$ per year more than Jane.

All her life Jane had to deal with the fact that people, both strangers and family members, were just less nice to her than to her siblings.

And, of course, Jane's siblings got married to rich, beautiful, smart and funny partners, whereas sometimes Jane felt like she was invisible to men's eyes.

\section{JANE'S PROBLEM}

Let us call Jane's problem "U" for the moment. Studies in psychology suggest that people who suffer from $U$ are disadvantaged compared to non $U$ people ${ }^{1}$. For instance:

1) U babies who were born pre-term receive less care from nurses and

${ }^{1}$ Webster Jr, M., \& Driskell Jr, J. E. (1983). Beauty as status. American Journal of Sociology, 140165. 
therefore recover more slowly than non U children ${ }^{2,3}$.

2) Mothers of $U$ infants tend to be less affectionate, playful, and attentive than mothers of non $U$ infants ${ }^{4,5}$. . Non $U$ infants elicit stronger motivation for caretaking ${ }^{7}$. Moreover, $\mathrm{U}$ children are rated as less adoptable ${ }^{8}$.

3) Teachers expect better performances from non U students ${ }^{9}$. Transgressions of $U$ children are judged more negatively ${ }^{10}$.

4) Once they grow up, U people have more difficulties at finding a job and they receive lower salaries, other things $(\mathrm{CV}$, training, expertise) being equal. According to economist Daniel Hamermesh, a non $U$ man can earn, over a life time, $\$ 230,000$ more than a U one ${ }^{11}$.

5) U people are less likely to be helped by strangers, friends and family members. ${ }^{12,13}$.

${ }^{2}$ S. Epps, "Labeling Effects of Infant Health and Parent Demographics on Nurses' Ratings of Preterm Infant Behavior," IMHJ (University of Nebraska Medical Center) 14, no. 3 (1993): pp. 182-191.

${ }^{3}$ K. L. Badr and B. Abdallah, "Physical Attractiveness of Premature Infants Affects Outcome at Discharge from NICU (Neonatal Intensive Care Unit)," Infant Behavior and Development 24, no. 1 (2001): pp. 129- 133.

${ }^{4}$ Langlois, J. H., Ritter, J. M., Casey, R. J. \& Sawin, D. B. 1995: Infant attractiveness predicts maternal behaviors and attitudes. Dev. Psychol. 31, 464-472.

${ }^{5}$ D. M. Buss, Evolutionary Psychology: The New Science of the Mind (Boston: Allyn \& Bacon, 1999); and M. Daly, "Evolutionary Theory and Parental Motives," in Mammalian Parenting, ed. N. A

${ }^{6}$ J. Mann, "Nurturance or Negligence: Maternal Psychology and Behavioral Preference Among Preterm Twins," in The Adapted Mind: Evolutionary Psychology and the Generation of Culture, ed. J. H. Barkow, L.Cosmides, and J. Tobby (New York: Oxford University Press, 1992): pp. 367-390.

7 M. L. Glocker, D.D. Langleben et al. Baby Schema in Infant Faces Induces Cuteness Perception and Motivation for Caretaking in Adults, Ethology, 115 (2009) 257-263.

${ }^{8}$ Volk, A. \& Quinsey, V. L. 2002: The influence of infant facial cues on adoption preferences. Hum. Nat. 13, 437-455.

9 J. Rich, "Effects of Children's Physical Attractiveness on Teacher's Evaluations" Journal of Educational Psychology 67 (1975): pp. 599-609.

${ }^{10}$ Dion, K. K. Physical attractiveness and evaluationsof children's transgressions. Journal of Personality and Social Psychology, 1972, 24, 207-213.

${ }^{11}$ D.Hamermesh, Beauty Pays: why Attractive People are more Successful, Princeton University Press, 2013.

12 Athanasiou, R. \& Greene, P. Physical attractiveness and helping behavior. Proceedings of the 81st Annual Convention of the American Psychological Association, 8, 1973, 289-290

${ }_{13}$ Benson, P. L., Karabenick, S. A. \& Lerner, R. M. Pretty pleases: the effects of physical attractiveness, race, and sex on receiving help. Journal of Experimental Social Psychology, 12, 1976, 409-415. 
6) In the courtroom, $U$ people are considered innocent less often than non $U$ ones, and the imposed sentence on them is often more severe. Also, if $U$ people are victims of a crime, they receive less generous indemnifications ${ }^{14,15,16}$.

7) $U$ college students have less romantic dates than non $U$ ones ${ }^{17}$, and non $U$ people are perceived to have (and often actually have) happier marriages ${ }^{18}$.

8) U people are perceived at first sight as less likable and friendly and as having poor mental health ${ }^{19}$. They are also perceived as less resilient, less academically and professionally competent and less skilled at performing various tasks, from writing essays to selling various products ${ }^{20}$.

\section{WHAT IS “U”?}

Jane's "problem" was her unattractiveness -or ugliness ${ }^{21}$, the fact that her nose was way too big, her eyes too small, her lips too thin, her jaw protruding. Jane had thin, dry hair, sticking out ears, and her skin was dotted with freckles, moles and pimples. When comparing her life to her sisters' life, she felt that, had she been attractive, things would have fared better for her.

Beauty effects have been studied and observed in different domains of life. Human attraction to beauty is a by-product of evolutionary adaptive mechanisms: "[B]eauty is a universal part of human experience, and it provokes pleasure, rivets attention, and impels actions that help ensure the

${ }^{14}$ B. W. Darby and D. Jeffers, "The Effects of Defendant and Juror Attractiveness on Simulated Courtroom Trial Decisions," Social Behavior and Personality: An International Journal 16, no. 1 (1988): pp. 39-50.

15 S. J. McKelvie and J. Coley, "Effects of Crime Seriousness and Offender Facial Attractiveness on Recommended Treatment," Social Behavior and Personality: An International Journal 21, no. 4 (1993): pp. 265-277.

${ }^{16}$ Abwender, D. A., and K. Hough. "Interactive Effects of Characteristics of Defendant and Mock Juror on U.S. Participants' Judgment and Sentencing Recommendations." The Journal of Social Psychology 141, no. 5 (2001): 603-616.

17 Huston, T. L. 1973. "Ambiguity of Acceptance, Social Desirability, and Dating Choice."Joumal of Experimental Social Psychology 9:32-42.

${ }_{18}^{18}$ Berscheid, E., and E. Walster. 1974. "Physical Attractiveness." Pp. 157-215 in Advances in Experimental Social Psychology, vol. 7, edited by L. Berkowitz. New York: Academic Press.

${ }_{19}$ Miller, A. G. 1970. "Role of Physical Attractiveness in Impression Formation." Psychonomic Science 19:241-43.

${ }^{20}$ Dion, Karen, Ellen Berscheid, and Elaine Walster. "What is beautiful is good." Journal of personality and social psychology 24.3 (1972): 285.

${ }^{21}$ Unattractiveness and ugliness (or bad looks) are not equivalent. Being attractive or not has to do with various aspects of an individual (intelligence, kindness, sense of humor etc.) and not only with her looks. However, in this paper I will use the terms interchangeably because in the psychology literature on the topic they are used as synonymous. 
survival of our genes. Our extreme sensitivity to beauty is hard-wired, that is, governed by circuits in the brain shaped by natural selection"22.

Discrimination against people considered to have bad looks according to widespread social and/or psychobiological standards is sometimes referred to as "lookism", to highlight the similarity to other forms of discrimination, such as "sexism", "racism" and "ageism". As Deborah Rhode put it, "anywhere from 12 to 16 percent of workers believe that they have been subject to such bias, a percentage that is in the same vicinity, or greater, than those reporting gender, racial, ethnic, age, or religious prejudice" 23 .

Although the majority of people tend not to appreciate their own discriminatory practices against the unattractive, lookism is more widespread and pervasive than people think.

\section{THE COST OF UNATTRACTIVENESS}

Unattractiveness does not impose just a psychological and social burden, but also an economic one. Economists have been interested in attractiveness (or lack of it) for a long time. From an economic perspective, beauty is interesting because physical attractiveness is, to a certain extent, measureable and it has an impact on people's income, and this impact is also measurable and can be converted into monetary equivalents ${ }^{24,25}$.

Studies on attractiveness usually refer to a 1 to 5 scale: people considered unattractive are the ones who, according to subjects asked to assess the level of attractiveness, score between 1 and 2, average people score 3 and attractive ones score 4 or 5 .

Studies in economics show that attractive people earn more than average ones who, in turn, earn more than unattractive ones. Daniel Hamermesh, who studied the effects of physical appearance on income, concluded that in the US women rated as having a below average level of attractiveness, i.e. the ones rated 1 or 2 and representing the $15 \%$ of the population, receive a $4 \%$ lower pay than average looking women; women considered above average (score 4 or 5) earn $8 \%$ more than average-looking women ${ }^{26}$.

\footnotetext{
22 Etcoff, N.; Survival of the Prettiest: the Science of Beauty, New York: Anchor Books, 1999, P.29

${ }^{23}$ Rhode, D. L.; The Beauty Bias: the Injustice of Appearance in Life and Law, Oxford University Press 2010 (P.9)

${ }^{24}$ Hamermesh, D. S. (2011). Beauty pays: Why attractive people are more successful. Princeton University Press.

${ }^{25}$ Borland, J., \& Leigh, A. (2014). Unpacking the beauty premium: What channels does it operate through, and has it changed over time?. Economic Record, 90(288), 17-32.

${ }^{26}$ Hamermesh, D. S. (2011). Beauty pays: Why attractive people are more successful.

Princeton University Press.
} 
The differences are even more noticeable among men: below average looking men earn $22 \%$ less than average ones, and above average ones earn 3\% more than average ones. Since an American worker earns, on average, 20\$ per working hour, Hamermesh estimates that in a life-time a good-looking worker earns about 230,000\$ more than a non attractive one, and 140,000\$ more than an average looking worker ${ }^{27}$.

Hamermesh's conclusions are supported by other studies conducted in other economic areas, including Britain ${ }^{28}$, Shangai ${ }^{29}$, and Australia ${ }^{30}$.

But the economic cost of lookism does not amount just to the money unattractive people lose because they are either unemployed or paid less than their average or good looking co-workers. According to the last data released by the American Society for Aesthetic Plastic Surgery ${ }^{31}$, in 2014 in the US more than 10 million cosmetic treatments were performed, for a total cost of more than 12 billion dollars. Women had more than 9.6 million cosmetic procedures, a $429 \%$ increase from 1997. People invest a lot of time, money and effort in their looks, and the ones who have been less lucky in the genetic lottery probably have to bear some extra economic costs in order to look good.

\section{DEBUNKING SOME BEAUTY MYTHS}

\section{Beauty is in the eye of the beholder}

People often say that "beauty is in the eye of the beholder", meaning that there is no objective standard of beauty. However, empirical studies suggest that there is substantial consensus on what physical attractiveness is and who is attractive or not. People may disagree about whether Jude Law is more or less attractive than Brad Pitt, but it is unlikely that someone finds Woody Allen or Gerard Depardieu more good looking than Jude Law or Brad Pitt, and this is because attractiveness is, at least to a certain extent, objective.

The evolutionary reason why attractiveness is so important is that it works as a good heuristic to evaluate the fitness of other members of our species. Studies have shown that attractiveness is an indicator of fitness, health,

\footnotetext{
27 ibidem

${ }^{28}$ Harper, B. (2000). Beauty, stature and the labour market: a British cohort study. Oxford Bulletin of Economics and Statistics, 62(s1), 771-800.

${ }^{29}$ Hamermesh, D. S., Meng, X., \& Zhang, J. (2002). Dress for success-does primping pay?. Labour Economics, 9(3), 361-373.

${ }^{30}$ Borland, J., \& Leigh, A. (2014). Unpacking the beauty premium: What channels does it operate through, and has it changed over time?. Economic Record, 90(288), 17-32.

31 http://www.surgery.org/media/news-releases/the-american-society-for-aesthetic-plasticsurgery-reports-americans-spent-more-than-12-billion-in-2014--pro(Last accessed 29/12/2015).
} 
quality and reproductive value ${ }^{32}$ and that it takes us just 150 milliseconds and no eye movement to assess whether a stranger is attractive or not ${ }^{33}$.

At least three foundational elements of facial attractiveness have been identified: (1) averageness; (2) symmetry; and (3) sexual dimorphism ${ }^{34,35}$.

(1) Averageness is considered attractive because a facial pattern closer to average is linked to genetic diversity (an "averaged" face is created by averaging together a certain number of faces. The "averaged" face is usually considered more attractive than the individual faces used to create the "averaged" face). Genetic diversity, in turn, confers better resistance to parasites.

(2) Symmetry reveals the ability to resist mutations, pathogens and toxins during the foetal development.

(3) Extremes in dimorphic traits (i.e., very feminine or masculine traits) signal a good set of genes. Since sex hormones tend to suppress the immune system, individuals with extreme dimorphic features show to have a particularly good immune system, because otherwise they would have been debilitated by the presence of high level of sexual hormones in their organism.

These foundational elements of beauty (averageness, symmetry, and sexual dimorphism) are found across a variety of cultures and through human history, and that is why beauty can be considered the result of species-typical psychological adaptation.

\section{Don't we judge a book by its cover?}

Another saying suggests that we should not judge a book by its cover, meaning that we should not judge a person by their appearance. This is certainly good advice, but do we actually follow it? A seminal paper by Dion

\footnotetext{
32 Langlois, J. H., Kalakanis, L., Rubenstein, A. J., Larson, A., Hallam, M., \& Smoot, M. (2000). Maxims or myths of beauty? A meta-analytic and theoretical review. Psychological bulletin, 126(3), 390.

${ }^{33}$ Goldstein, A. G., \& Papageorge, J. (1980). Judgments of facial attractiveness in the absence of eye movements. Bulletin of the psychonomic society, 15(4), 269-270.

${ }^{34}$ Bashour, M. (2005). Is an Objective Measuring System for Facial Attractiveness Possible?. University of Toronto.

${ }^{35}$ Little, Anthony C., Benedict C. Jones, and Lisa M. DeBruine. "Facial attractiveness: evolutionary based research." Philosophical Transactions of the Royal Society B: Biological Sciences 366.1571 (2011): 1638-1659.
} 
et al. suggests that people tend to instinctively assume that "what is beautiful is good" and attribute positive personality characteristic to beautiful people ${ }^{36}$. A meta-analyses study by Langlois et al. suggests that attractive people, both children and adults, are evaluated significantly more favourably than their unattractive counterparts, even by familiar perceivers. The studies on children took into account four categories, namely their perceived (1) social appeal; (2) academic/developmental competence; (3) adjustment; and (4) interpersonal competence. Overall, the $75 \%$ of attractive children and (only) the $25 \%$ of unattractive ones were judged to be above the mean for these four categories $^{37}$ (p.400).

Things do not seem to fare out better for adults. In the case of adults the parameters taken into account by Langlois and colleagues were (1) occupational competence; (2) social appeal; (3) interpersonal competence; and (4) adjustment. The researchers found out that attractive adults were judged more favourably than unattractive ones (62\% vs $38 \%$ ). Their occupational competence were perceived as much higher (70\% vs 30\%), they were judged as having more social appeal (62\% vs $38 \%$ ) and to be more interpersonally competent (61\% vs 39\%) and better adjusted (56\% vs $44 \%)^{38}$.

Another study found that "The obese child was reliably ranked last, even lower than children with gross physical disabilities, not only by children from different socioeconomic and ethnic backgrounds, but even by children who themselves had physical disabilities". Also the obese adults interviewed for this study showed aversion against the obese children. These results seem to suggest that the stigma against obese children is worse than stigma toward disabled ones ${ }^{39}$.

Perhaps the most worrisome aspect of these results is that, since what people project on to others often turns into a self-fulfilling prophecy ${ }^{40,41}$, treating people as if they were, for instance, less academically or professionally competent than they actually are can change their self-perception and therefore have a negative impact on their lives.

\footnotetext{
${ }^{36}$ Dion, K., Berscheid, E., \& Walster, E. (1972). What is beautiful is good. Journal of personality and social psychology, 24(3), 285.

${ }^{37}$ Langlois, J. H., Kalakanis, L., Rubenstein, A. J., Larson, A., Hallam, M., \& Smoot, M. (2000). Maxims or myths of beauty? A meta-analytic and theoretical review. Psychological bulletin, 126(3), 390-423 (p.400)

${ }^{38}$ Langlois et al. 2000, op.cit, p.401.

${ }^{39}$ Latner, J. D., \& Stunkard, A. J. (2003). Getting worse: the stigmatization of obese children. Obesity research, 11(3), 452-456, p.452.

${ }^{40}$ Snyder, M., E. D. Tanke, and E. Berscheid. 1977. "Social Perception and Interpersonal Behavior: On the Self-fulfilling Nature of Stereotypes of Personality and Social Psychology 35:656-66.

${ }^{41}$ Jussim, Palumbo, Chatman, Madon, and A. Smith. Stigma and Self Fulfilling Prophecies in (Edited by) Todd F. Heatherton, Robert E. Kleck, Michelle R. Hebl, and Jay G. Hull The Social Psychology of Stigma, Guilford Press, 2000
} 


\section{Different cultures hold completely different standards of beauty}

The same meta-analysis of studies on attractiveness by Langlois et al. ${ }^{42}$ found that people agree about what constitutes beauty and about who is attractive or not. In particular, these studies suggest that attractiveness ratings are reliable both in same culture and in cross-cultural and cross-ethnic studies.

The hypothesis that there is a universal standard of beauty seems to be supported also by studies on very young children (from 14 hours after birth). In these experiments, children are found to stare for longer at faces rated as attractive by adults and they look away, or even cry, when in front of people rated as unattractive by adults. These children are too young to explain this phenomenon with cultural influences ${ }^{43}$.

Beauty is an inter-subjective property, in the sense that almost all individuals capable of making judgments about beauty agree on certain standards of beauty. Such a view has been often challenged. For instance Naomi Wolf, in her book The Beauty Myth, suggested that "“Beauty" is not universal or changeless [...\}; the Maori admire a fat vulva, and the Padung, droopy breasts. Nor is "beauty" a function of evolution: its ideals change at a pace far more rapid than that of the evolution of species" 44 .

Wolf is right in pointing out that within some groups a certain physical characteristic is considered attractive, whilst in a different one it may be considered unattractive. It is also true that some characteristics can be considered attractive in a given society at a certain time, and less attractive in the same society after a few years or decades. These facts apparently contradict the scientific studies above mentioned. In the next paragraph I will propose a way to reconcile these apparently conflicting hypotheses.

\section{TWO APPROACHES TO BEAUTY (AND LACK OF IT)}

The debate on beauty as a philosophical and political problem is rather stagnant due to a polarization of approaches ${ }^{45}$ : the evolutionary-essentialist one and the constructionist-social one.

According to the former, beauty is a biological adaptation, as the studies mentioned in the previous sections seem to suggest. From an evolutionary

\footnotetext{
${ }^{42}$ Langlois et al. op.cit.

${ }^{43}$ Langlois, J. H., Ritter, J. M., Roggman, L. A., \&Vaughn, L. S. (1991). Facial diversity and infant preferences for attractive faces. Developmental Psychology, 27, 79-84.

${ }^{44}$ Wolf, N., The Beauty Myth: How Images of Beauty are used against Women, New York: Perennial, 2002 (p.12).

${ }^{45}$ L.Tietje, S. Cresap, Is Lookism Unjust?: the Ethics of Aesthetics and Public Policy Implications, Journal of Libertarian Studies, 19(2):31-50, 2005.
} 
perspective, being beautiful has been an advantage in terms of reproductive potential. We are naturally hard-wired to recognize beauty and, as a consequence, people who do not display the physical characteristics that we are evolutionary- driven to appreciate, are discriminated against.

For instance, the aforementioned experiments on very young children who show that they prefer to look at faces which are considered attractive by adults, seem to strongly support the idea that we are somehow hardwired in our preference for some particular features. Similarly, the fact that people across different times, geographic areas and cultures agree on who is attractive or not, seem to robustly support the idea that cultural, social or historical differences do not matter too much when it comes to attractiveness. On the contrary, the constructionist-social approach stresses the issue of "beautification" and suggests that beauty is a social construct, i.e. something culturally determined and aimed at perpetrating inequality and discrimination against certain groups. In particular, feminist thinkers have defended the idea that standards of beauty are imposed on women by a maledominated society $46,47,48,49$.

Studies in psychology also support the thesis that people's perception of what is attractive is influenced by their social and cultural environment. For instance, anorexia nervosa was an unknown disease in the Fiji until TV was introduced. A few months following the introduction of TV, anorexia started spreading among the female population ${ }^{50}$. It seems plausible that such rapid increase in the number of anorexic women was caused by exposure to a new (westernized) paradigm of beauty according to which thinness -pretty muchequals beauty. On the other hand, exposure to more inclusive media models has been proved to have a better effect on self-concern about looks ${ }^{51}$.

In 2004 the personal care brand Dove commissioned a study on beauty ("The Real Truth About Beauty Study"52) to Harvard psychologist Nancy Etcoff and psychotherapist Susie Orbach (London School of Economics). According to

\footnotetext{
${ }^{46}$ K.P. Morgan, Women and the Knife: Cosmetic Surgery and the Colonization of Women's Bodies, Hypatia, Volume 6, Issue 3, pages 25-53, September 1991

${ }^{47}$ Shari L. Dworkin, Faye Linda Wachs, Body Panic: Gender, Health and the Selling of Fitness, New York University Press, 2009.

${ }^{48}$ Wolf, N.; op.cit.

${ }^{49}$ Sontag, S., The Double Standard of Aging, Saturday Review, September, 1972, 29-30.

${ }^{50}$ Becker, A. E., Burwell, R. A., Herzog, D. B., Hamburg, P., \& Gilman, S. E. (2002). Eating behaviours and attitudes following prolonged exposure to television among ethnic Fijian adolescent girls. The British Journal of Psychiatry, 180(6), 509-514.

${ }^{51}$ Halliwell, E., Easun, A., \& Harcourt, D. (2011). Body dissatisfaction: Can a short media literacy message reduce negative media exposure effects amongst adolescent girls?. British journal of health psychology, 16(2), 396-403.

52 The study can be found here http://www.dove.us/docs/pdf/19 0810 The Truth About Beauty-White Paper 2.pdf (last accessed 12/01/2016).
} 
the study women reckon that the media have a negative impact on their perception of themselves, and in particular, that the beauty paradigms portrayed in the media are way too narrow.

\section{BETWEEN THE EVOLUTIONARY-ESSENTIALIST AND THE CONSTRUCTIONIST-SOCIAL APPROACHES}

According to the social-constructionist approach, in order to solve psychological, economic and social issues related to discrimination based on looks, we should change the current paradigm of beauty. Society shapes the paradigm of attractiveness by portraying more often some features and by praising or blaming some physical features. For instance, Caucasian features are the most widely represented in the western media. There are, of course, historical, economic and political reasons that explain this over-representation of Caucasian individuals, and this fact has an enormous impact in shaping the current ideal of beauty. As Nancy Etcoff noticed, "Beauty judgments are sensitive barometers of social status. In all countries the economically dominant group has put forward its own ethnic features as the standard of beauty, and in widespread dominance mimicry, other groups tend to follow the group's lead"53. There is no evolutionary reason (but there are historical and economic ones) why Caucasian features are presented in the media as the most attractive ones, or for why at this particular historical moment very skinny women are considered more attractive than ones with a higher Body Mass Index (BMI). Given the fact that such preferences are not hard-wired, but acquired through social influence, there are good reasons to think that by spreading a more inclusive ideal of attractiveness in society, we might be able to change the current narrow paradigm of beauty. For example, if more women with cellulite or higher BMI were portrayed in magazines and in TV shows, it is likely that cellulite and higher BMI would stop being considered an unattractive feature of women's body.

Individual or societal preferences for some particular features are influenced by internal elements (such as hormonal state); context (the gender of the person assessing the level of attractiveness) and exposure (the kind of faces we see more often). Exposure impact may be particularly relevant if we wanted to use the media to (re)shape preferences. As Little, Jones and DeBruine point out, "We are unlikely to have an inbuilt average face and what is average must be calculated from experience ${ }^{\prime \prime 54}$. This could mean that, if we were exposed from birth to a larger variety of facial features, the average

\footnotetext{
${ }^{53}$ Etcoff, N. op.cot. 1999, p. 117.

${ }^{54}$ Little, A. C., Jones, B. C., \& DeBruine, L. M. (2011). Facial attractiveness: evolutionary based research. Philosophical Transactions of the Royal Society B: Biological Sciences, 366(1571), 1638-1659. (p. 1650).
} 
face computed in our brain would be more inclusive of less commonly seen features.

However, it is still plausible that some preferences cannot be changed. Or perhaps they cannot be changed by mere increase of exposure. For instance, even though the number of obese people has increased over the last decades, and therefore exposure to obese people has increases, stigma of obese people has not decreased and, quite to the contrary, it has increased over the last decades. Perhaps changing preferences that developed over very long lapses of time and complex adaptive mechanisms is difficult, and we currently don't know how to modify such preferences. But it is very important to find out whether such preferences can be changed, and if so, through which kind of intervention.

In order to find a reasonable normative solution to such discriminatory behaviours by taking into account the most relevant issues raised by both the social-constructionist and the evolutionary-essentialist approaches to beauty, it is therefore important to distinguish between features that are considered foundational elements of attractiveness (e.g. symmetry, sexual dimorphism, healthy skin, a certain hips to waist or shoulder to waist ratio) and characteristics whose aesthetical assessment is heavily influenced by societal elements (such as BMI, eye shape, skin colour). These two different kinds of elements (evolutionary and socially constructed) need to be analysed and discussed separately because of the different solutions we might put in place to address them, not because of differences in their ontological or epistemic status. It might be that for people who are affected by a severe lack of facial symmetry, aesthetic surgery is, at the moment, the best option, and that therefore we have some reasons to promote or in some way support access to aesthetic surgery for certain people. On the contrary, a social intervention might be the most effective way to address socially constructed problems of unattractiveness. For instance, we should address differently the case of a woman with asymmetrical eyes and the cases of a woman who is overweight (without being morbidly obese) or a woman who wants a treatment to bleach her dark $\operatorname{skin}^{55}$. In the two last cases, it might be argued that the most effective solution would be to change the main beauty paradigm: if more women with dark skin or non-skinny women were portrayed in the media, people would (hopefully) adjust to new beauty standards ${ }^{56}$. An integrated approach to beauty according to which we distinguish between characteristics we are hard-wired or socially influenced to consider attractive or unattractive seems to be a path worth exploring.

\footnotetext{
${ }^{55}$ Sander E. Gilman, Creating Beauty to Cure the Soul: Race and Psychology in the Shaping of Aesthetic Surgery, Durham, NC: Duke University Press, 1998.

${ }_{56}$ Rosemarie Tong, Hilde Lindermann, in David Benatar (ed), Cutting the Core, Rowman \&Littlefield Publishing Group, 2006.
} 


\section{LOOKISM AND THE LAW}

Societal change can often be supported by legal change, as we have witnessed in the case of discrimination against disabled people, black people, women and homosexuals. Deborah Rhode argued that the law should do more in to protect people from discrimination based on looks. For instance, Rhode argues, disability law should be extended so as to cover discrimination of non morbidly obese people and, in general, anti-discriminatory legislations already in use could broaden their scope so as to protect people from various forms of discrimination based on looks. Such changes would have a positive effect in the fight against lookism and would have a positive effect in terms of enabling unattractive people to have equal opportunities ${ }^{57}$.

One might object that, even if unattractive people were protected by the law, there would be very limited cases where it would be possible to prove that someone has been discriminated against on the basis of their looks. This objection seems to apply to many other forms of discriminations: how do we know if an Afro-American person, or a blind person did not get a job because they were actually less good than other applicants in the job-relevant skills or because of some unfair discrimination against them? After several decades of legal, social and cultural battles against discrimination based on gender, sexual preferences, disability, race, and religion, we are all much more aware of this sort of prejudice, so that we can detect people discriminating against someone for such reasons. However, lookism may be a particularly difficult case because people are not accustomed to assessing their own lookist practices, or to recognizing that discrimination has been perpetrated against them because of their unattractive features.

A few cities and districts have attempted to give protection to victims of lookism: in Michigan, District of Columbia, Howard County, San Francisco, Santa Cruz, Madison and Urbana, legal measures have been taken in order to punish such form of discrimination ${ }^{58}$.

Over the years, some American courts had to deliberate about various complaints of plaintiffs against employers accused of discrimination based on looks. For instance, in 2000 Joseph Connor sued a McDonalds restaurant in Connecticut because, despite their initial decision to hire him, they never asked him to start working as a cook at their restaurant. Connor weighed 420 pounds $(190 \mathrm{~kg}$ ) and he argued that McDonalds did not give him the job

\footnotetext{
${ }^{57}$ Rhode, D. L. (2009). The injustice of appearance. Stanford Law Review, 1033-1101.

${ }^{58}$ Ibidem
} 
because he was obese. According to Connor, his rights, protected under the Disability act, were violated, and the court agreed with him ${ }^{59}$.

However, legislations aimed at punishing discrimination based on looks cannot be of any help if people are not capable of recognising it. Connor is an exception and lookism remains a silent, neglected and invisible form of discrimination.

According to Hamermesh, we could also consider the option of compensating people for economic loss due to their unattractiveness. He notices that insurances compensate people for prospective economic loss when they have an accident that somehow thwarts their professional future. For instance, if someone gets a scar on their face after a car accident, they might get an economic compensation that takes into account their age, prospective employment loss etc. The option of compensating unattractive people might work well for economic loss, but obviously it would not compensate for loss of romantic opportunities or decrease in wellbeing caused by the psychological impact of discrimination in such social contexts.

Also, since laws aimed at preventing discrimination of the unattractive cannot be effective to solve the problem until people become aware of the fact that this form of discrimination exists, it is unlikely that a victim of lookism would ask for a compensation because they might not be aware of it.

Many Western countries provide cosmetic and plastic surgery under the national health system schemes to people who suffer from disfigurements that are commonly considered impairments (cleft palates that cause speech impairments) or are relatively easy to fix (protruding ears). Different countries have different legislations with enormous differences among them with respect to the kind of treatment a person might be able to obtain from the public health system. According to these legislations free cosmetic surgery or free cosmetic treatments are not provided for just any kind of feature the patient is not happy with. It usually has to be proved that a condition significantly affects the psychological wellbeing of the patient, and it has to be proved that there are some objective parameters whereby the person has a deformity. But what counts as a deformity is not free from cultural influences, and characteristics that fall under the umbrella of "deformity" are nowadays so wide that the medical term "deformity" has become quite anaemic (protruding ears are considered a "deformity" but quite obviously a person with protruding ears is not "deformed").

\footnotetext{
${ }^{59}$ Connorv.MdDanald's, etal Connecticut District Court, Case No. 3:02-cv-00382-SRU

http://www.ctd.uscourts.gov/sites/default/files/opinions/031703.SRU .Connor.pdf (last accessed 13/01/2016)
} 


\section{LOOKISM AND COSMETIC SURGERY}

Usually, at least in public health systems, resources are allocated so as to give priority to the treatment of severe illness and impairments: the more impairing a condition,, the more it is considered deserving of therapeutic intervention.

I will now introduce some examples to show that the subjective perception of what is a condition negatively affecting wellbeing can be different from the common medical "objective" assessment of illness and impairment.

Subject $A$ suffers from a condition $X$ that reduces dramatically the quality of her life. Because of this condition, $A$ does not have a normal social life, doesn't have many friends and/or partners, is depressed and/or cannot do her job properly. A even tried to fix her problem by herself, because she couldn't find doctors willing or able to help her, but this just made the situation more serious and she almost died.

We don't know what condition $X$ is, but we know that it causes true, continuous and profound suffering to $A$ by dramatically decreasing her level of wellbeing.

Now I will reformulate my examples, and this time I will attribute a precise name to condition $X$.

Case 1) $A$ suffers from apotemnophilia, a rather rare condition whereby the person doesn't recognize one or more limbs as part of her own body. The psychological suffering is so profound that the person is very often depressed and tries to cut the unwanted limb, causing sometimes a gangrene that then forces doctors to amputate the limb. At the moment, the only way to increase the quality of apotemnophiliacs' life is to amputate the leg or arm they don't want. In cases when this intervention has been performed, patients reported to be happy and satisfied with the result ${ }^{60}$. In this case amputation, an intervention that is usually considered pejorative, is a therapeutic treatment.

Case 2) $A$ is a man, 20 year old, from Saudi Arabia. He feels that his male body doesn't fit with his own perception of himself and therefore he wants to change sex and become a woman. Because of his condition, and because of the social context where he lives, he can't live his sexual life and his social life

\footnotetext{
${ }^{60}$ Savulescu, J. (2007). Autonomy, the good life, and controversial choices. In: R. Rhodes, L. P. Francis, A. Silvers (Eds.), The Blackwell guide to medical ethics (pp.17-37). Blackwell Publishing Ltd.
} 
as he would like to. Therefore he decides to buy on the Internet some hormonal treatments without consulting a doctor, even if he knows that this could damage his health. Nevertheless, $A$ thinks that his life is not worth living if he is trapped in a male body and therefore he will keep on using these hormones without any medical supervision unless he finds a doctor that prescribes him the right treatment.

Case 3) $A$ is a 15 year old girl, she is pregnant and lives in a country where abortion is illegal. She thinks that she is too young to have a child and wants to have an abortion. Since in her country abortion is illegal, her friends suggest to use some prostaglandin pills that are commonly used for gastric ulcer but cause miscarriages as a side effect. The ingestion of an excessive amount of these pills causes a severe bleeding and $A$ has to go to the emergency hospital.

In these examples $X$, the condition that causes suffering to $A$ is (1) the presence of 4 healthy limbs, (2) being a man , (3) being pregnant.

None of these conditions is, by definition and objectively, pathological. Quite to the contrary, many of us would be desperate if they'd lose an arm, and many others would be really happy to be pregnant. Or, also, many men are really happy to be men and would never like to be a woman.

These examples show that conditions that are not pathological in an absolute sense can cause as much suffering or even more suffering than conditions considered pathologies by most people (for instance, there are many deaf people and many people affected by dwarfism who are happy with their lives and wouldn't like to be treated). Indeed, not all medical treatments commonly provided in hospitals around the world are life-saving ones or aimed at removing physical or mental impairments. For instance, many countries in the world provide free IVF, although being childfree- or sterile is not something that necessarily causes suffering (some people are happy to be child-free, whereas some other ones choose to become sterile by undergoing vasectomy). Being sterile has a negative impact just on the wellbeing of people who want to have children, and doesn't affect the ones who don't want to be parents.

In the light of the studies mentioned at the beginning of this paper, it is plausible to argue that at least some people suffer a decrease in wellbeing because of their looks. In a study on formerly obese people, researchers found out that even though such people acknowledged that obesity is not an extremely disabling condition, they would have preferred to have a major handicap such as being deaf, blind, or to have a leg amputated instead of 
being again morbidly obese ${ }^{61}$. Similarly, the study showing that obese children are more discriminated against than disabled children suggests that it might be that being unattractive has equally negative consequences as having a physical impairment. Actually, it might be that in a certain cultural and social context being blind or deaf has less of a negative impact on wellbeing than being extremely unattractive, perhaps because ugly people feel (and perhaps are) more discriminated or stigmatized than people with major handicaps.

If what matters the most is a person's quality of life and not the kind of condition that prevents her from experiencing a higher level of wellbeing or the kind of treatment she needs in order to have a good life, then it is plausible that in some cases moral reasons in favour of providing a person who is extremely unattractive with cosmetic surgery and/or social/economic/legal support and protection are stronger than we might think.

When we focus on the goal of increasing levels of wellbeing and pay close attention to what people need in order to be happy (or at least to reduce their suffering), we can better assess the effectiveness of a treatment. And even if we move beyond the concept of impairment or illness, we can still provide some objective evaluation about different conditions. Leaving the notion of impairment behind does not necessarily imply that priorities cannot be assessed in the healthcare context: no rational agent would think that a cold is worse than cancer, or that a broken nose is worse than a heart attack, because the consequences brought by a cold and a by a fractured nose are not as bad as the consequences caused by cancer or a heart attack. However, there are situations where it is not so easy to evaluate what is worse between two cases. Sometimes, for instance, we don't have all the information we need to evaluate the situation, or we are incapable of assessing the impact of a certain condition on wellbeing.

Traditionally, we have referred to the distinction between impairing conditions and non impairing ones in order to assess priorities in healthcare ${ }^{62}$. Although this distinction is useful and should play a role in decisions about allocation of resources, it sets inadequate parameters to assess the impact of a certain condition on an individual, and the effectiveness of treatments aiming at increasing the level of wellbeing of different individuals.

I am not defending here an extreme version of the social account of disability, but I am rather arguing that psychological suffering should count regardless

\footnotetext{
${ }^{61}$ Rand, C. S., \& Macgregor, A. M. (1991). Successful weight loss following obesity surgery and the perceived liability of morbid obesity. International Journal of Obesity, 15(9), 577-579.

${ }^{62}$ Daniels, N., 2000. Normal functioning and the treatment-enhancement distinction,

Cambridge Quarterly of Healthcare Ethics, 9, 3: 309-322
} 
of the feature that causes it- may it be a physical impairment, an illness or a socially penalizing physical feature.

\section{CONCLUSIONS}

Discrimination based on looks is an issue we need to think about because it negatively affects the wellbeing of bad looking people. Depending on the explanation of this phenomenon one embraces, one can get to different conclusions about the best course of action to fight lookism.

A social constructivist approach, based on the idea that beauty is a cultural by-product, focuses mainly on the changes to beauty paradigms in society. This is definitely a goal we need to pursue because we know that current paradigms of beauty are not inclusive enough and they affect the way people perceive themselves and their body image. We urgently need to get rid of fictional beauty models, such as the ones which exist just on heavily photoshopped cover pages of fashion magazines, and make sure that different sizes, skin colours, eye shapes, breast shapes etc. are represented.

However, social and cultural interventions are unlikely to solve all the problems related to lookism. As highlighted by the evolutionary-essentialist approach, there are characteristics that we probably would not find attractive even if the media were widely portraying these characteristics. A symmetric face, healthy skin, a precise hips to waist ratio and some facial proportions are elements which we are hard-wired to find attractive, regardless of social influences. In some cases, then, it would be effective to intervene through cosmetic surgery (at the moment) or through genetic engineering (in the future). Public funding could be used for people who cannot afford these treatments and who are psychologically and/or economically damaged by severe lack of attractiveness.

We already provide free public treatments (such as IVF, abortion etc.) for conditions which are not impairments per se.

Since medicine is not just about saving lives but is also about promoting health, and since health is not just the absence of disease but also "a complete state of physical, mental and social well-being"63, we need to consider the possibility that being extremely unattractive might have an equally negative or even more negative impact on wellbeing than some conditions traditionally considered disabling, and that therefore we should allocate medical resources accordingly.

More work needs to be done in order to establish the relevant criteria for inclusion in the category of people for whom a medical/surgical intervention would be the most effective and ethically appropriate way of reducing

\footnotetext{
${ }^{63}$ Preamble to the Constitution of the World Health Organization, 1948.
} 
suffering and discrimination, as well as to establish to what extent access to medical/surgical interventions for these people should be promoted. Far from providing an answer to this type of questions, this paper wants to be an attempt to start a serious, constructive and hopefully productive bioethical discussion about a problem which, although so far confined almost exclusively to the fields of psychological and economic studies, certainly has relevant bioethical implications. 